J Am Chem Soc. 2016 March 23; 138(11): 3655-3658. doi:10.1021/jacs.6b01078.

\title{
Hydroxymethylation beyond Carbonylation: Enantioselective Iridium Catalyzed Reductive Coupling of Formaldehyde with Allylic Acetates via Enantiotopic $\pi$-Facial Discrimination
}

\author{
Victoria J. Garza and Michael J. Krische* \\ University of Texas at Austin, Department of Chemistry, Austin, TX 78712, USA
}

\begin{abstract}
Chiral iridium complexes modified by SEGPHOS catalyze the 2-propanol mediated reductive coupling of branched allylic acetates 1a-1o with formaldehyde to form primary homoallylic alcohols 2a-2o with excellent control of regio- and enantioselectivity. These processes, which rely on enantiotopic $\pi$-facial discrimination of $\sigma$-allyliridium intermediates, represent the first examples of enantioselective formaldehyde $\mathrm{C}-\mathrm{C}$ coupling beyond aldol addition.
\end{abstract}

\section{Graphical abstract}

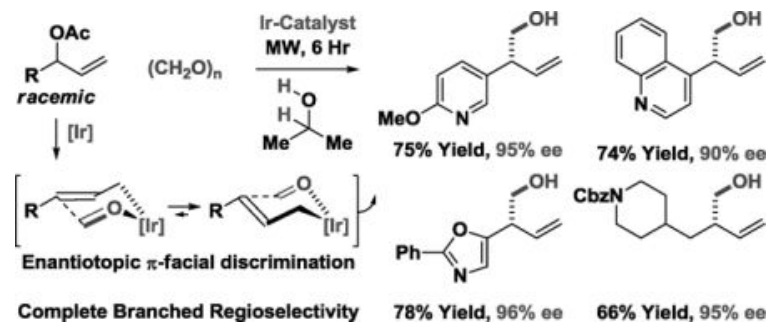

Enantiotopic facial discrimination of electrophilic allylmetal species is well established in asymmetric allylic alkylation (W, Pd, Mo, Ir) (Scheme 1, eq. 1). However, despite nearly four decades of work on enantioselective carbonyl allylation, ${ }^{-}$this mode of enantioselection is unknown in the context of nucleophilic allylmetal species, where work has focused exclusively on asymmetric additions to aldehydes or ketones to form chiral a-stereogenic secondary or tertiary alcohols, respectively (Scheme 1, eq. 2). Nucleophilic allylations of formaldehyde to form chiral $\beta$-stereogenic primary homoallylic alcohols have not been described. Indeed, the only catalytic enantioselective $\mathrm{C}-\mathrm{C}$ couplings of formaldehyde reported, to date, involve asymmetric aldol addition.'

Merging the chemistry of transfer hydrogenation and carbonyl addition, formaldehyde (or methanol) mediated hydrohydroxymethylations of diverse $\pi$-unsaturated reactants (allenes, dienes and alkynes) were developed." While these processes are efficient and regioselective

Corresponding Author. mkrische@ mail.utexas.edu.

Supporting Information Available: Experimental procedures and spectral data. HPLC traces corresponding to racemic and enantiomerically enriched samples. Single crystal X-ray diffraction data for compound 3a. This material is available free of charge via the internet at http://pubs.acs.org. 
in contexts where carbonylation/hydroformylation is not, enantioselective variants have not been established, nor has the hydroxymethylation of allylic acetates been explored. Here, we apply a chiral iridium catalyst to the enantioselective reductive coupling of allylic acetates with formaldehyde to form chiral $\beta$-stereogenic primary homoallylic alcohols via enantiotopic $\pi$-facial discrimination of $\sigma$-allyliridium intermediates (Scheme 1, eq. 3 ). These processes constitute the first examples of enantioselective formaldehyde $\mathrm{C}-\mathrm{C}$ coupling beyond aldol addition.

The use of paraformaldehyde as an electrophilic partner in asymmetric nucleophilic allylation poses several challenges. First, high levels of enantioselectivity require intervention of a single geometrical isomer of the $\sigma$-allylmetal species in the carbonyl addition event. Our collective data are consistent with a catalytic mechanism wherein carbonyl addition occurs by way of a closed chair-like transition structure.' Second, as established in studies on the stereochemistry of mechanistically related aldol additions, competition between chair-like $v s$ boat-like transition structures increases with decreasing steric demand of the reactants, which inverts the enantiotopic nucleophile $\pi$-face undergoing addition. Finally, in the presence of group 9 metals, paraformaldehyde will transform to synthesis gas, which can promote a variety of side reactions and act as a catalyst poison.

Cognizant of these potential obstacles, initial optimization experiments were undertaken. Gratifyingly, it was found that the indicated $\pi$-allyliridium $C, O$-benzoate complex modified by $(S)$-SEGPHOS promotes the reductive coupling of the 4-bromophenyl substituted allylic acetate $1 \mathbf{a}(150 \mathrm{~mol} \%)$ with paraformaldehyde $(100 \mathrm{~mol} \%)$ to provide the desired product, the primary homoallylic alcohol 2a, in 54\% yield and $94 \%$ ee as a single regioisomer (Table 1). It was postulated that synthesis gas generated upon decomposition of paraformaldehyde might contribute to the formation of catalytically inactive iridium carbonyl complexes. This hypothesis was corroborated by the observance of absorptions at $2125 \mathrm{~cm}^{-1}$ in IR spectra taken from aliquots of crude reaction mixtures. Hence, $\mathrm{N}$-methyl morpholine oxide (NMO), which is commonly used for the oxidative removal of carbonyl ligands, was employed as an additive. As hoped, the addition of NMO proved to be beneficial, allowing homoallylic alcohol 2a to be isolated in $85 \%$ yield and $97 \%$ ee. However, this yield could not be reproduced on larger scale due to solubility issues involving both paraformaldehyde and NMO. Fortunately, it was found that microwave heating largely restored the isolated yield of 2a with the advantage of significantly shortened reaction times.

To assess scope, optimized conditions were applied to the reductive coupling of paraformaldehyde with diverse branched allylic acetates 1a-1o (Table 2). As illustrated in the formation of primary homoallylic alcohols $\mathbf{2 a}-\mathbf{2 e}$, a variety of substituted aryl groups are tolerated, including ortho-substituted aryl moieties ( $\mathbf{2 c}$ ). The formation of compounds $\mathbf{2 f}-\mathbf{2 k}$ establish the tolerance of these conditions toward $\mathrm{N}-, \mathrm{S}$ - and $\mathrm{O}$-bearing heterocycles. In each case, aryl- and heteroaryl-substituted substituted products $\mathbf{2 a - 2} \mathbf{k}$ are formed in good yield with uniformly high levels of enantioselectivity, consistent with good partitioning of $(E)$ and (Z)- $\sigma$-allyliridium isomers in the carbonyl addition event (eq. 4). Even in the case of branched 


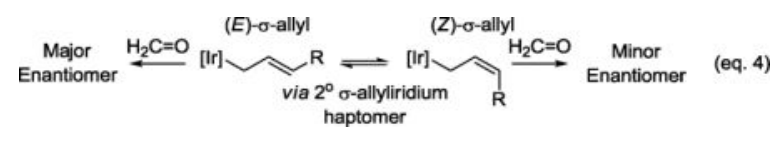

(eq. 4)

allylic acetates substituted by styryl groups (11) or alkyl chains (1m-10), high levels of enantioselectivity are retained. In all cases, complete levels of branch-regioselectivity are observed. Attempted redox-neutral hydroxymethylations wherein methanol serves dually as reductant and formaldehyde precursor were inefficient due to transesterification and transfer hydrogenation of the terminal olefin of the allylic acetate.

The products of reductive coupling serve as useful building blocks in chemical synthesis (Scheme 2). For example, rhodium catalyzed hydroformylation of adduct 2a provides a lactol, which upon treatment with pyridinium chlorochromate (PCC) is converted to the enantiomerically enriched $\delta$-lactone 3a (eq. 5). The absolute stereochemistry of 3a was determined by single crystal X-ray diffraction and is the basis for the stereochemical assignments of compounds 2a-2o. Conversion of alcohol 2a to the corresponding acrylic ester, followed by ring-closing metathesis, delivers the $\alpha, \beta$-unsaturated $\delta$-lactone $4 a$ (eq. 6). Amination of the alcohol moiety of $\mathbf{2 a}$ by way of the $p$-toluene sulfonate was challenging due to competing elimination. However, treating the $p$-toluene sulfonate derived from 2a with sodium azide in DMF delivered the primary azide in good yield. Reduction of the azide provided the amine, which was isolated as the $N$-Boc amide 5a (eq. 7).

A catalytic mechanism and stereochemical have been proposed (Scheme 3). Entry into the catalytic cycle occurs via protonolytic cleavage of the $\pi$-allyliridium $C, O$-benzoate complex mediated by 2-propanol to furnish the indicated iridium 2-propoxide complex. $\beta$-Hydride elimination with loss of acetone generates an iridium hydride, which upon deprotonation forms an anionic iridium(I) species. Ionization of the allylic acetate delivers the monosubstituted $\pi$-allyliridium complex. Complete levels of branch-regioselectivity accompanied by high levels of enantioselectivity suggest formaldehyde addition occurs predominantly by way of the primary $(E)-\sigma$-allyliridium haptomer through a closed 6-centered transition structure.' Protonolytic cleavage of the resulting homoallylic alkoxide mediated by 2 propanol regenerates the iridium 2-propoxide complex to close the catalytic cycle. The absolute stereochemical course of the carbonyl addition event is consistent with our previously proposed stereochemical model. Allylic acetate recovered from the reaction is racemic, indicating kinetic resolution does not occur in the ionization event.

In summary, we report the first enantioselective formaldehyde $\mathrm{C}-\mathrm{C}$ couplings beyond aldol addition. Specifically, chiral iridium complexes modified by SEGPHOS catalyze the 2propanol mediated reductive coupling of branched allylic acetates 1a-1o with formaldehyde to form primary homoallylic alcohols $\mathbf{2 a - 2 o}$ with complete control of regioselectivity and uniformly high levels of enantioselectivity. This process provides access to products of hydroxyalkylation that are inaccessible using classical carbonylative methods' and support 
the feasibility of related transformations, including the non-carbonylative aminomethylation of branched allylic acetates.

\section{Supplementary Material}

Refer to Web version on PubMed Central for supplementary material.

\section{Acknowledgments}

The Robert A. Welch Foundation (F-0038) and the NIH-NIGMS (RO1-GM069445) are acknowledged for partial support of this research. Chinh Ngo, Zhicheng Zhang and Nicole Behnke are acknowledged for technical assistance.

\section{References}

1. For seminal examples of enantiotopic facial discrimination in electrophilic $\pi$-allyl complexes based on W, Pd, Mo and Ir, respectively, see:(a) Lloyd-Jones GC, Pfaltz A. Angew Chem Int Ed Engl. 1995; 34:462.(b) Trost BM, Krische MJ, Radinov R, Zanoni G. J Am Chem Soc. 1996; 118:6297. (c) Janssen JP, Helmchen G. Tetrahedron Lett. 1997; 38:8025.(d) Trost BM, Hachiya I. J Am Chem Soc. 1998; 120:1104.

2. For selected reviews on enantioselective carbonyl allylation, see:(a) Ramachandran PV. Aldrichim Acta. 2002; 35:23.(b) Denmark SE, Fu J. Chem Rev. 2003; 103:2763. [PubMed: 12914480] (c) Kennedy JWJ, Hall DG. Angew Chem, Int Ed. 2003; 42:473.(d) Yu C-M, Youn J, Jung H-K. Bull Korean Chem Soc. 2006; 27:462.(e) Marek I, Sklute G. Chem Commun. 2007; 1683(f) Hall DG. Synlett. 2007; 1644(g) Lachance H, Hall DG. Org React. 2008; 73:1.(h) Yus M, González-Gómez JC, Foubelo F. Chem Rev. 2011; 111:7774. [PubMed: 21923136]

3. For selected examples of enantioselective carbonyl allylation using chirally modified allylmetal reagents, see:(a) Herold T, Hoffmann RW. Angew Chem Int Ed. 1978; 17:768.(b) Hoffmann RW, Herold T. Chem Ber. 1981; 114:375.(c) Hayashi T, Konishi M, Kumada M. J Am Chem Soc. 1982; 104:4963.(d) Brown HC, Jadhav PK. J Am Chem Soc. 1983; 105:2092.(e) Roush WR, Walts AE, Hoong LK. J Am Chem Soc. 1985; 107:8186.(f) Reetz MT. Pure Appl Chem. 1988; 60:1607.(g) Short RP, Masamune S. J Am Chem Soc. 1989; 111:1892.(h) Corey EJ, Yu C-M, Kim SS. J Am Chem Soc. 1989; 111:5495.(i) Seebach D, Beck AK, Imwinkelzied R, Roggo S, Wonnacott A. Helv Chim Acta. 1987; 70:954.(j) Riediker M, Duthaler RO. Angew Chem, Int Ed. 1989; 28:494.(k) Panek JS, Yang M. J Am Chem Soc. 1991; 113:6594.(1) Kinnaird JWA, Ng PY, Kubota K, Wang X, Leighton JL. J Am Chem Soc. 2002; 124:7920. [PubMed: 12095334] (m) Hackman BM, Lombardi PJ, Leighton JL. Org Lett. 2004; 6:4375. [PubMed: 15524487] (n) Burgos CH, Canales E, Matos K, Soderquist JA. J Am Chem Soc. 2005; 127:8044. [PubMed: 15926828]

4. For selected examples of enantioselective carbonyl allylation using achiral allylmetal reagents in combination with chiral catalysts, see:(a) Furuta K, Mouri M, Yamamoto H. Synlett. 1991; 561(b) Costa AL, Piazza MG, Tagliavini E, Trombini C, Umani-Ronchi A. J Am Chem Soc. 1993; 115:7001.(c) Keck GE, Tar-bet KH, Geraci LS. J Am Chem Soc. 1993; 115:8467.(d) Denmark SE, Coe DM, Pratt NE, Griedel BD. J Org Chem. 1994; 59:6161.(e) Denmark SE, Fu J. J Am Chem Soc. 2001; 123:9488. [PubMed: 11562250] (f) Lachance H, Lu X, Gravel M, Hall DG. J Am Chem Soc. 2003; 125:10160. [PubMed: 12926924] (g) Wada R, Oisaki K, Kanai M, Shibasaki M. J Am Chem Soc. 2004; 126:8910. [PubMed: 15264818] (h) Rauniyar V, Hall DG. Angew Chem Int Ed. 2006; 45:2426.(i) Rauniyar V, Zhai H, Hall DG. J Am Chem Soc. 2008; 130:8481. [PubMed: 18540580] (j) Lou S, Moquist PN, Schaus SE. J Am Chem Soc. 2006; 128:12660. [PubMed: 17002355] (k) Barnett DS, Moquist PN, Schaus SE. Angew Chem, Int Ed. 2009; 48:8679.(1) Jain P, Antilla JC. J Am Chem Soc. 2010; 132:11884. [PubMed: 20690662]

5. For selected reviews on enantioselective carbonyl allylation via Nozaki-Hiyama-Kishi coupling, see: (a) Avalos M, Babiano R, Cintas P, Jiménez JL, Palacios JC. Chem Soc Rev. 1999; 28:169.(b) Bandini M, Cozzi PG, Umani-Ronchi A. Chem Commun. 2002; 919(c) Hargaden GC, Guiry PJ. Adv Synth Catal. 2007; 349:2407. 
6. For selected reviews covering carbonyl allylation via umpolung of $\pi$-allyls, see:(a) Masuyama, Y. Advances in Metal-Organic Chemistry. Liebeskind, LS., editor. Vol. 3. JAI Press; Greenwich: 1994. p. 255(b) Tamaru, Y. Handbook of Organopalladium Chemistry for Organic Synthesis. Negishi, E-i; de Meijere, A., editors. Vol. 2. Wiley; New York: 2002. p. 1917(c) Tamaru, Y. Perspectives in Organopalladium Chemistry for the XXI Century. Tsuji, J., editor. Elsevier; Amsterdam: 1999. p. 215(d) Kondo T, Mitsudo T-A. Curr Org Chem. 2002; 6:1163.(e) Tamaru Y. Eur J Org Chem. 2005; 13:2647.(f) Zanoni G, Pontiroli A, Marchetti A, Vidari G. Eur J Org Chem. 2007; 22:3599.

7. For a recent review on enantioselective carbonyl allylation via transfer hydrogenation, see:Ketcham JM, Shin I, Montgomery TP, Krische MJ. Angew Chem Int Ed. 2014; 53:9142.

8. For selected examples of catalytic enantioselective redox-triggered carbonyl allylations employing allylic carboxylates as pronucleophiles, see:(a) Kim IS, Ngai M-Y, Krische MJ. J Am Chem Soc. 2008; 130:6340. [PubMed: 18444616] (b) Kim IS, Ngai M-Y, Krische MJ. J Am Chem Soc. 2008; 130:14891. [PubMed: 18841896] (c) Kim IS, Han SB, Krische MJ. J Am Chem Soc. 2009; 131:2514. [PubMed: 19191498] (d) Gao X, Townsend IA, Krische MJ. J Org Chem. 2011; 76:2350. [PubMed: 21375283] (e) Schmitt DC, Dechert-Schmitt A-MR, Krische MJ. Org Lett. 2012; 14:6302. [PubMed: 23231774] (f) Dechert-Schmitt A-MR, Schmitt DC, Krische MJ. Angew Chem Int Ed. 2013; 52:3195.(g) Shin I, Wang G, Krische MJ. Chem Eur J. 2014; 13382

9. For catalytic enantioselective Mukaiyama aldol additions of formaldehyde, see:(a) Ozasa N, Wadamoto M, Ishihara K, Yamamoto H. Synlett. 2003; 2219(b) Manabe K, Ishikawa S, Hamada T, Kobayashi S. Tetrahedron. 2003; 59:10439.(c) Ishikawa S, Hamada T, Manabe K, Kobayashi S. J Am Chem Soc. 2004; 126:12236. [PubMed: 15453735] (d) Kobayashi S, Ogino T, Shimizu H, Ishikawa S, Hamada T, Manabe K. Org Lett. 2005; 7:4729. [PubMed: 16209521] (e) Kokubo M, Ogawa C, Kobayashi S. Angew Chem Int Ed. 2008; 47:6909.

10. For catalytic enantioselective direct aldol additions of formaldehyde, see:(a) Kuwano R. Chem Commun. 1998; 71(b) Torii H, Naka-dai M, Ishihara K, Saito S, Yamamoto H. Angew Chem Int Ed. 2004; 43:1983.(c) Casas J, Sundén H, Córdova A. Tetrahedron Lett. 2004; 45:6117.(d) Fukuchi I, Hamashima Y, Sodeoka M. Adv Synth Catal. 2007; 349:509.(e) Mouri S, Chen Z, Matsunaga S, Shibasaki M. Chem Commun. 2009; 5138(f) Mase N, Inoue A, Nishio M, Takabe K. Bioorg Med Chem Lett. 2009; 3955(g) Boeckman RK Jr, Miller JR. Org Lett. 2009; 11:4544. [PubMed: 19757801] (h) Pasternak M, Paradowska J, Rogozińska M, Mlynarski J. Tetrahedron Lett. 2010; 51:4088.(i) Shirakawa S, Ota K, Terao SJ, Maruoka K. Org Biomol Chem. 2012; 10:5753. [PubMed: 22349720] (j) Yasui Y, Benohoud M, Sato I, Hayashi Y. Chem Lett. 2014; 43:556.(k) Meninno S, Fuoco T, Tedesco C, Lattanzi A. Org Lett. 2014; 16:4746. [PubMed: 25203623]

11. For catalytic hydrohydroxymethylation of allenes (a,b,c), dienes (d,e) and alkynes (f,g) to paraformaldehyde via $\mathrm{C}-\mathrm{C}$ bond forming transfer hydrogenation, see:(a) Ngai M-Y, Skucas E, Krische MJ. Org Lett. 2008; 10:2705. [PubMed: 18533665] (b) Moran J, Preetz A, Mesch RA, Krische MJ. Nat Chem. 2011; 3:287. [PubMed: 21430686] (c) Sam B, Montgomery TP, Krische MJ. Org Lett. 2013; 15:3790. [PubMed: 23841678] (d) Smejkal T, Han H, Breit B, Krische MJ. J Am Chem Soc. 2009; 131:10366. [PubMed: 19594163] (e) Köpfer A, Sam B, Breit B, Krische MJ. Chem Sci. 2013; 4:1876.(f) Bausch CC, Patman RL, Breit B, Krische MJ. Angew Chem Int Ed. 2011; 50:5687.

12. For reviews encompassing use of paraformaldehyde and methanol as $\mathrm{C} 1$-feedstocks in metal catalyzed C-C coupling, see:(a) Wu L, Liu Q, Jackstell R, Beller M. Angew Chem Int Ed. 2014; 53:6310.(b) Sam B, Breit B, Krische MJ. Angew Chem Int Ed. 2015; 54:3267.

13. For methanol-mediated Guerbet-type aldol reactions, see:(a) Chan LKM, Poole DL, Shen D, Healy MP, Donohoe TJ. An-gew Chem Int Ed. 2014; 53:761.(b) Shen D, Poole DL, Shot-ton CC, Kornahrens AF, Healy MP, Donohoe TJ. Angew Chem Int Ed. 2015; 54:1642.

14. Evans DA, Nelson JV, Taber T. Top Stereochem. 1982; 13:1.

15. Fuentes JA, Pittaway R, Clarke ML. Chem Eur J. 2015; 21:10645. and references cited therein. [PubMed: 26114239]

16. The absorption at $2125 \mathrm{~cm}^{-1}$ in IR is consistent with an iridium(III) carbonyl complex:(a) Vaska L, DiLuzio JW. J Am Chem Soc. 1961; 83:2784.(b) Vaska L. J Am Chem Soc. 1966; 88:4100. [PubMed: 5915161] 
17. Shen JK, Gao Y-C, Shi Q-Z, Basolo F. Coord Chem Rev. 1993; 128:69. and references cited therein.

18. for impact of large bite-angle ligands on regioselectivity in hydro-formylation see reference (a). For seminal use of XantPhos in linear regioselective hydroformylation, see reference (b):(a) Casey CP, Whiteker GT, Melville MG, Petrovich LM, Gavney JA Jr, Powel DR. J Am Chem Soc. 1992; 114:5535.(b) Kranen-burg M, van der Burgt YEM, Kamer PCJ, van Leeuwen PWNM, Goubitz KG, Fraanje J. Organometallics. 1995; 14:3081.

19. (a) Oda S, Sam B, Krische MJ. Angew Chem Int Ed. 2015; 54:8525.(b) Oda S, Franke J, Krische MJ. Chem Sci. 2016; 7:136. 
Prior Art: Enantiotopic $\pi$-facial discrimination of $\pi$-allylmetal species (ref. 1)

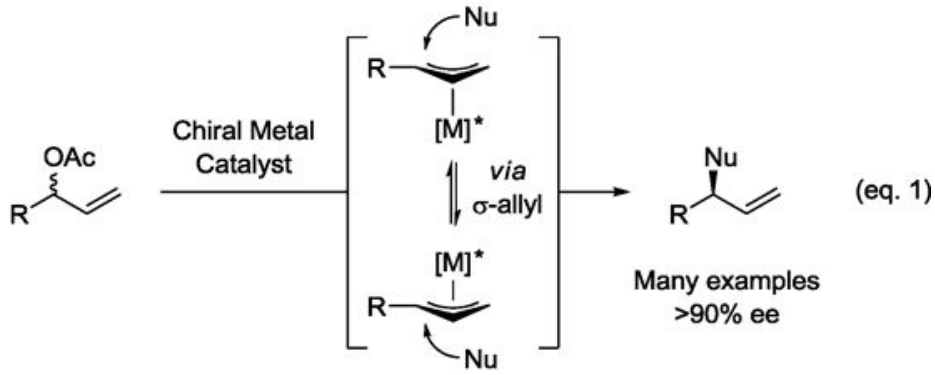

Prior Art: Enantiotopic $\pi$-facial discrimination of carbonyl compounds (ref. 2-8)

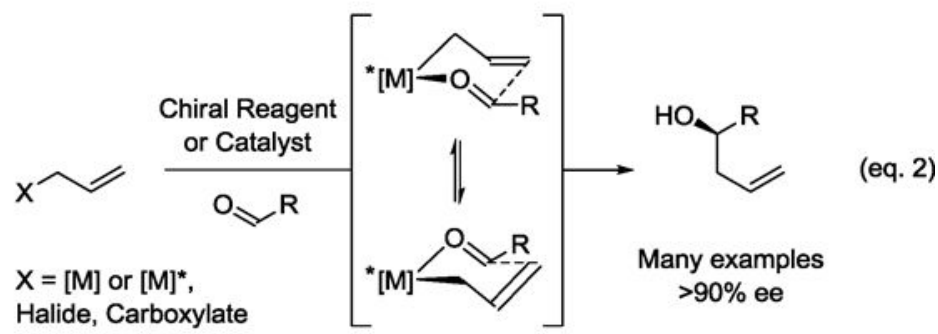

This Work: Enantiotopic $\pi$-facial discrimination of $\sigma$-allylmetal species

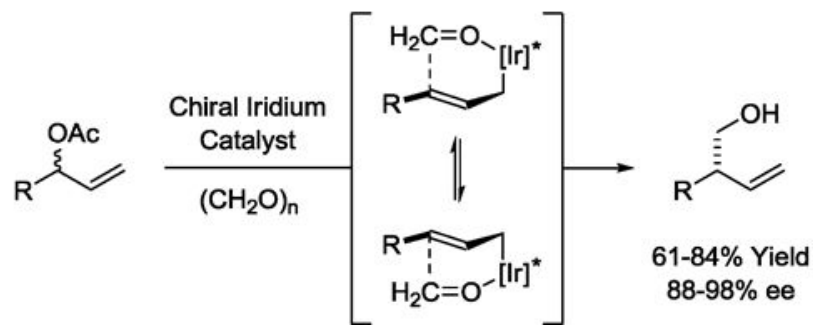

Scheme 1.

Enantiotopic $\pi$-facial discrimination in electrophilic and nucleophilic allylation. 
<smiles>C=C[C@@H](CO)c1ccc(Br)cc1</smiles><smiles>C=C[C@H](CO)c1ccc(Br)cc1</smiles>

2a<smiles>C=C[C@H](CO)c1ccc(Br)cc1</smiles>

1) $\mathrm{Rh}(\mathrm{CO})_{2}$ (acac) (3 mol\%) XantPhos (10 mol\%) $\mathrm{H}_{2} / \mathrm{CO}(1: 1,200 \mathrm{psi})$

THF $(0.15 \mathrm{M}), 70^{\circ} \mathrm{C}$ 2) PCC (300 mol\%) $\mathrm{NaOAc}(50 \mathrm{~mol} \%)$ $\operatorname{DCM}(0.1 \mathrm{M}), 25^{\circ} \mathrm{C}$

1) $\mathrm{ClCOCCH}=\mathrm{CH}_{2}$ (200 mol\%) $\mathrm{Et}_{3} \mathrm{~N}(300 \mathrm{~mol} \%)$

DCM $(0.07 \mathrm{M}), 0^{\circ} \mathrm{C}$ 2) Grubbs-II (5 mol\%) DCE $(0.05 \mathrm{M}), 65^{\circ} \mathrm{C}$

1) $\mathrm{TsCl}(120 \mathrm{~mol} \%)$ $\mathrm{Et}_{3} \mathrm{~N}$ (300 mol\%) DCM $(0.25 \mathrm{M}), 0^{\circ} \mathrm{C}$ 2) $\mathrm{NaN}_{3}(300 \mathrm{~mol} \%)$ DMF $(0.17 \mathrm{M}), 75^{\circ} \mathrm{C}$ 3) $\mathrm{LiAlH}_{4}(300 \mathrm{~mol} \%)$ $\operatorname{THF}(0.1 \mathrm{M}),-10^{\circ} \mathrm{C}$ 4) $\mathrm{Boc}_{2} \mathrm{O}$ (150 mol\%) $\operatorname{DCM}(0.65 \mathrm{M}), 25^{\circ} \mathrm{C}$

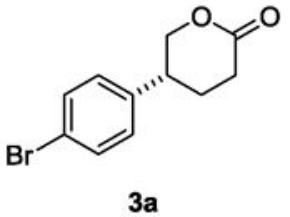

$86 \%$ Yield (2 Steps) 6:1 linear:branched X-Ray<smiles>O=C1C=C[C@H](c2ccc(Br)cc2)CO1</smiles>

97\% Yield (Step 1) $84 \%$ Yield (Step 2)

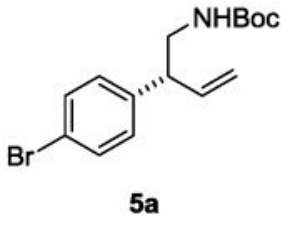

$88 \%$ Yield (Step 1) $81 \%$ Yield (Step 2) $86 \%$ (Steps 3 \& 4)

(eq. 5)

(eq. 6)

(eq. 7)

Scheme 2.

Elaboration of adduct 2a and assignment of absolute stereochemistry. ${ }^{\text {a }}$

${ }^{a}$ Yields are of material isolated by silica gel chromatography. 

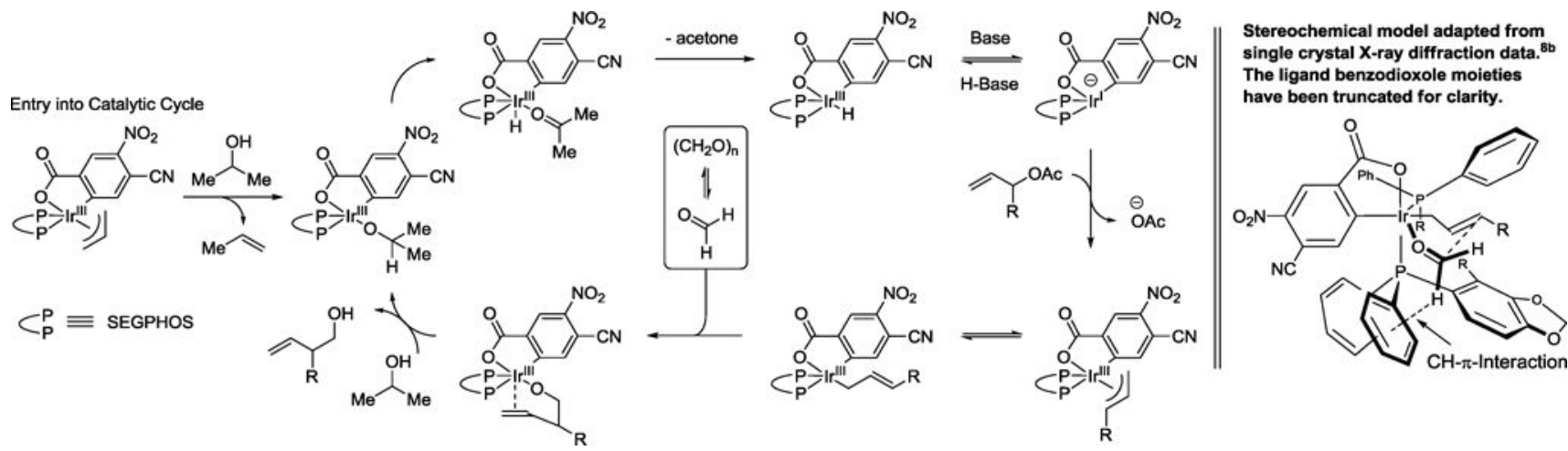

Scheme 3 .

General catalytic mechanism and stereochemical model. ${ }^{\mathrm{a}}$ 


\section{Table 1}

Selected optimization experiments in the enantioselective iridium catalyzed reductive coupling of allylic acetate 1a with formaldehyde illustrating the importance of NMO. ${ }^{a}$

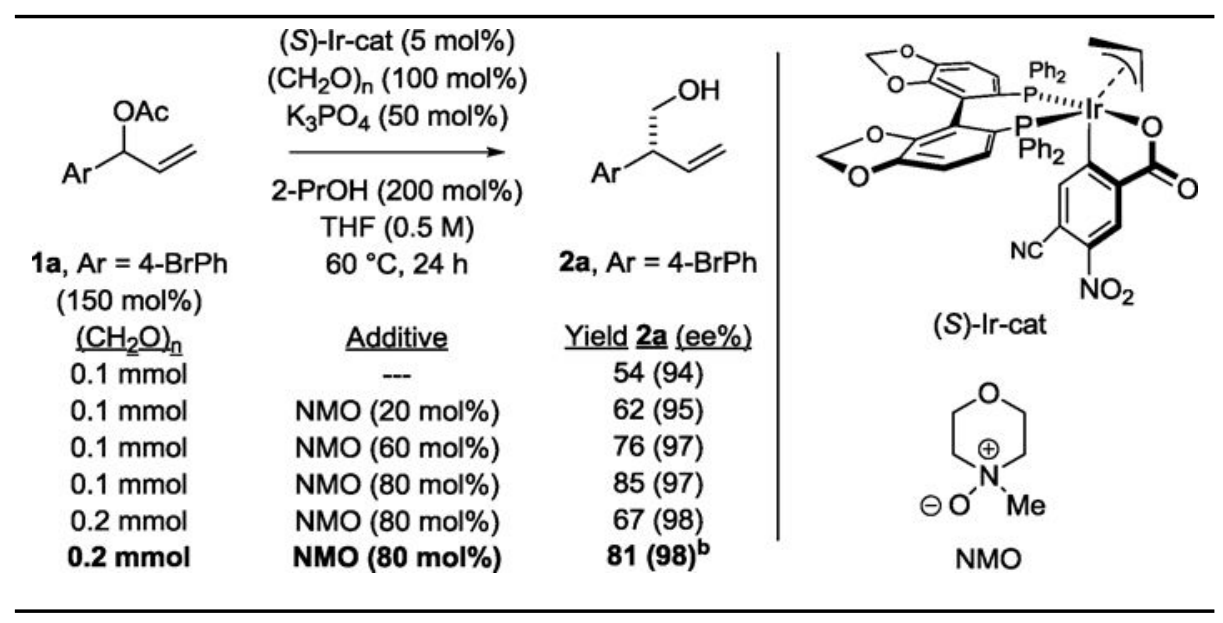

\footnotetext{
${ }^{a}$ Yields are of material isolated by silica gel chromatography. Enantioselectivities were determined by chiral stationary phase HPLC analysis. See Supporting Information for further experimental details

${ }^{b}$ Microwave heating, $6 \mathrm{~h}$.
} 


\section{Table 2}

Enantioselective iridium catalyzed reductive coupling of branched allylic acetates 1a-1o with formaldehyde to form primary homoallylic alcohols $\mathbf{2 a}-\mathbf{2 o} .^{a}$

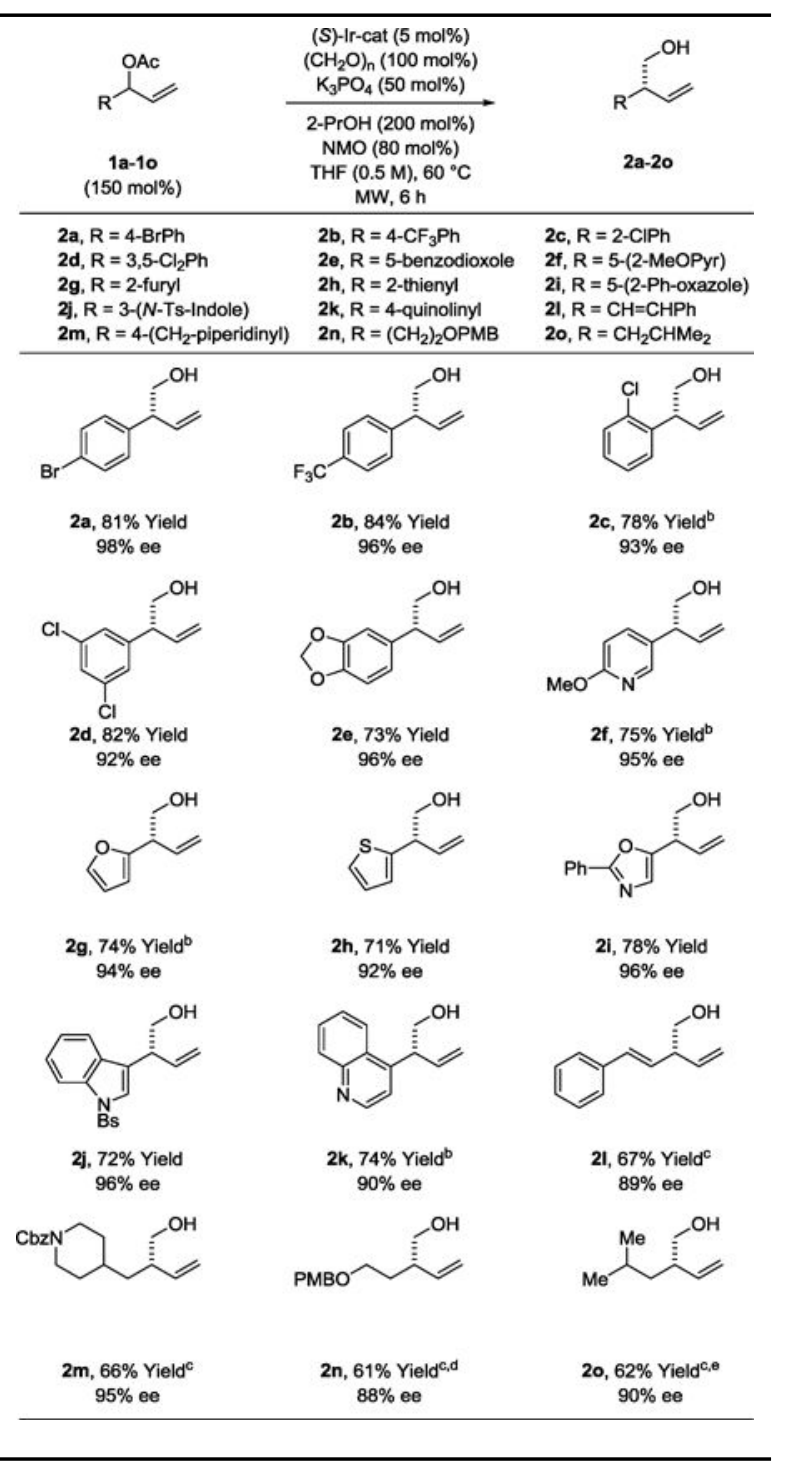

${ }^{a}$ Yields are of material isolated by silica gel chromatography. Enantioselectivities were determined by chiral stationary phase HPLC analysis. 2k, 8 h. 2l, 10 h. See Supporting Information for further experimental details.

$b_{80}{ }^{\circ} \mathrm{C}$.

${ }^{c} 70^{\circ} \mathrm{C}$.

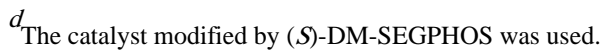

Isolated as the 4-nitrobenzoate due to volatility. 